\title{
Correction to: Emplacement controls for the basaltic-andesitic radial dikes of Summer Coon volcano and implications for flank vents at stratovolcanoes
}

\author{
A. G. Harp ${ }^{1} \cdot$ G. A. Valentine ${ }^{1}$ \\ Published online: 3 May 2018 \\ (C) Springer-Verlag GmbH Germany, part of Springer Nature 2018
}

Correction to: Bulletin of Volcanology (2018) 80: 16

https://doi.org/10.1007/s00445-018-1194-4

In the article "Emplacement controls for the basalticandesitic radial dikes of Summer Coon volcano and implications for flank vents at stratovolcanoes", the vertical axis for Fig. 8a was incorrectly labeled (i.e., the value for dikes per $\mathrm{km}^{2}$ ). The correct labels are instead one order of magnitude larger than originally given. The correct version of Figure 8 is given here. This error does not impact the analysis or interpretations of the investigation.

The online version of the original article can be found at https://doi.org/ 10.1007/s00445-018-1194-4

A. G. Harp

agharp@buffalo.edu

1 Department of Geology, University at Buffalo, 126 Cooke Hall, Buffalo, NY 14260, USA 

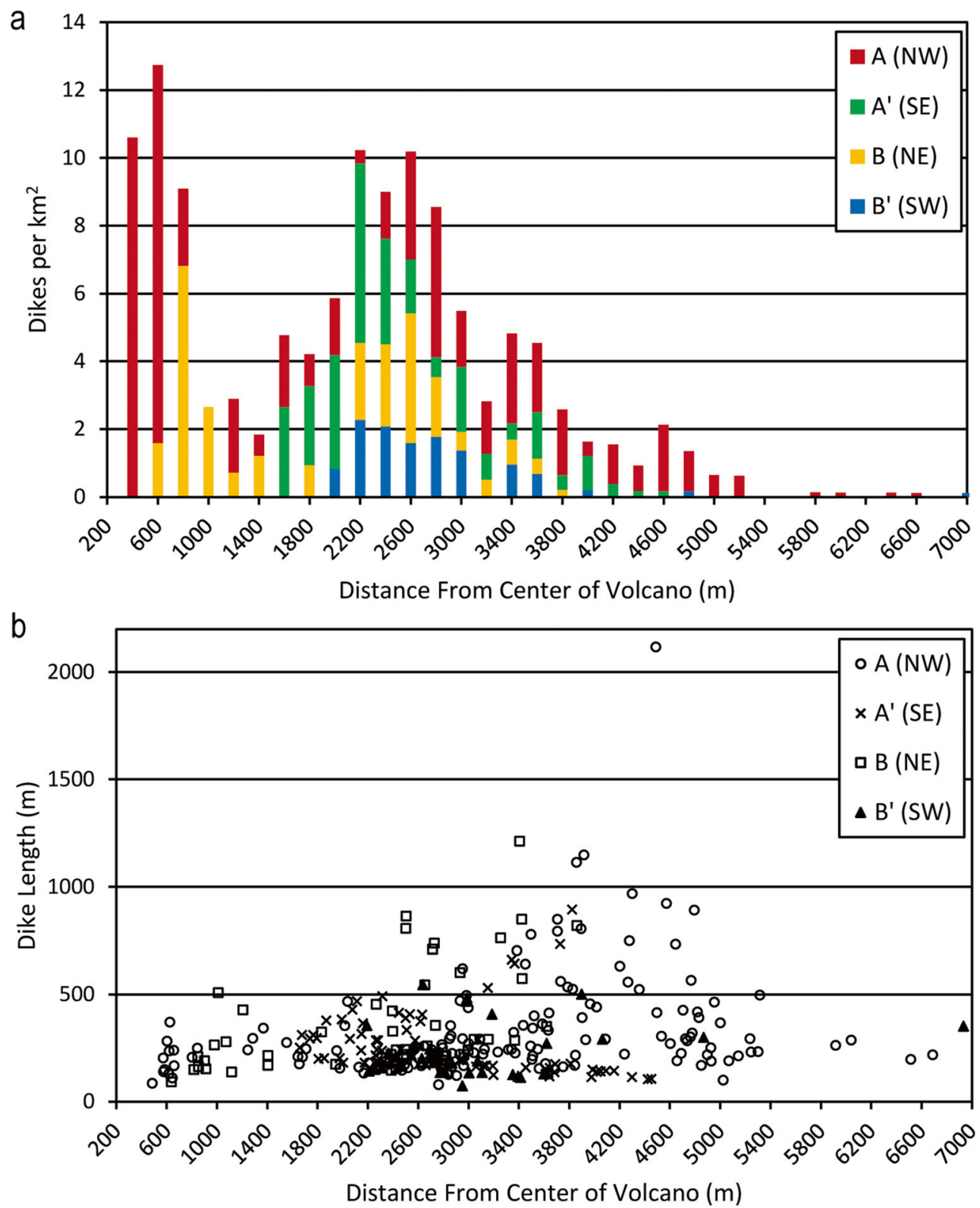

Fig. 8 Distance plots combining our data with the existing USGS geological map of Summer Coon (Lipman 1976). a Dike distance distribution (quadrants defined in Fig. 2). b Minimum dike lengths 